\title{
EL PROCESO CONSERVADOR
}

\author{
Andrés Perea, Arquitecto
}

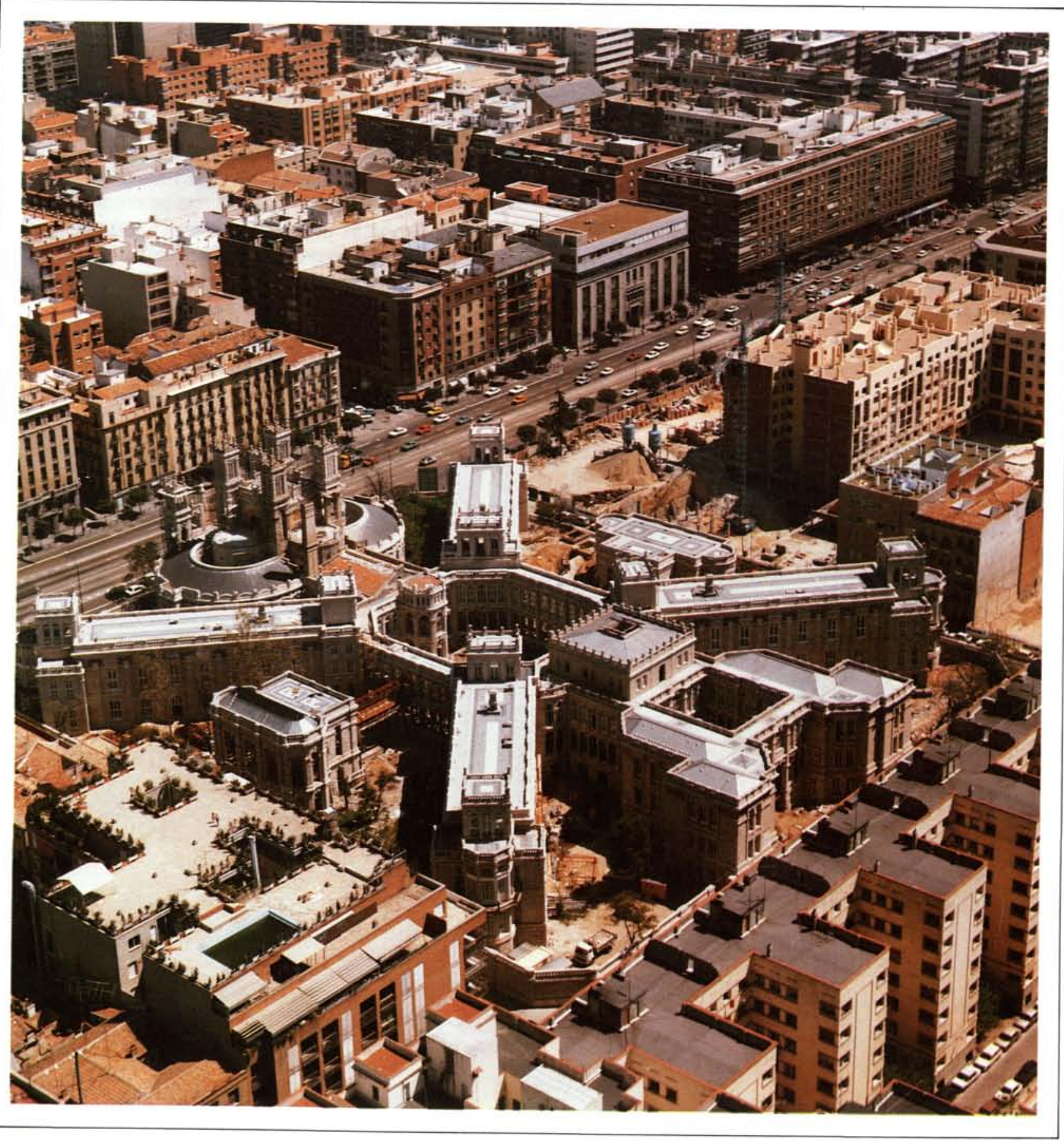


Cuando en 1918 se terminan los trabajos del Hospital de Maudes, Strawinsky ha estrenado la Consagración de la Primavera, Picasso ha pintado las Señoritas de la calle Aviñón, Adolf Loos ha construido la casa STEI. NER y sólo una década más tarde Mies Van der Röhe construye el Pabellón Barcelona.

Palacios es, no obstante, un arquitecto dotado de un talento excepcional no sólo en la intuición del espacio sino sobre todo en el moldeado de las formas que lo cierran.

Al margen del decalaje temporal en que se produce esta fábrica, es indudable la calidad de la Iglesia en todos sus aspectos arquitectónicos y formales y el interés tanto de la organización espacial del conjunto como de la belleza del resultado de espacios o elementos de cierre, revestimiento y equipamiento.

Hemos sido conscientes de que, al margen de apreciaciones sociohistóricas, el Hospital de Maudes es un objeto coherente y vigoroso con leyes precisas, herméticas que debiamos respetar.

En general la organización relativa de los espacios, algún espacio en sí mismo y sobre todo el material tectónico básico con que Palacios definió su construcción.
La obra de Palacios, por otra parte, no se detuvo en esta obra de juventud. El propio arquitecto generó una importante evolución en su "estilo" hasta aproximarse relativamente a la modernidad en sus últimas realizaciones.

De estas consideraciones que resumen reflexiones críticas y procesos de aprendizaje mucho más amplios, hemos planteado los criterios de actuación en el edificio.

Esta actuación exige superar las convenciones metodológicas de diseño arquitectónico y sus particiones cronológicas, Ideación-Proyecto-Construcción, para entender que es preciso actuar de forma más compleja y en un proceso continuo y dilatado.

Este edificio, como toda la arquitectura previa o al margen de los procesos constructivos heredados de la revolución industrial, contenian en su esencia un concepto del tiempo distinto, concepto sincrónico de la ideación a la realización que además se produce en dimensión temporal, mucho más dilatado que en nuestros dias. En este medio, el acto proyectual disfruta de una fricción intensa con el objeto arquitectónico y de un proceso dialéctico de ida y vuelta, edificio-diseño, enriquecido por ei reciclaje de cada experiencia.

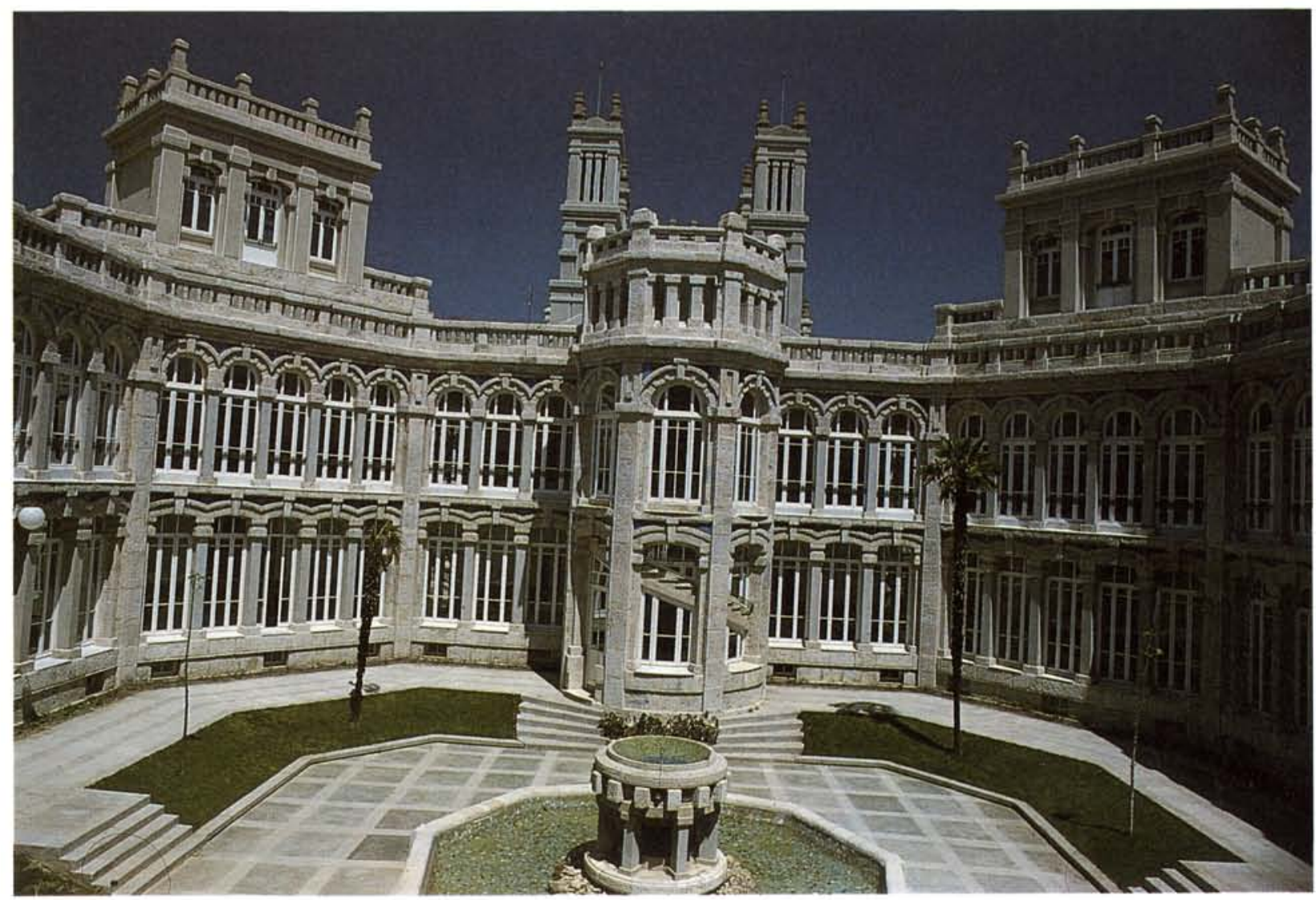




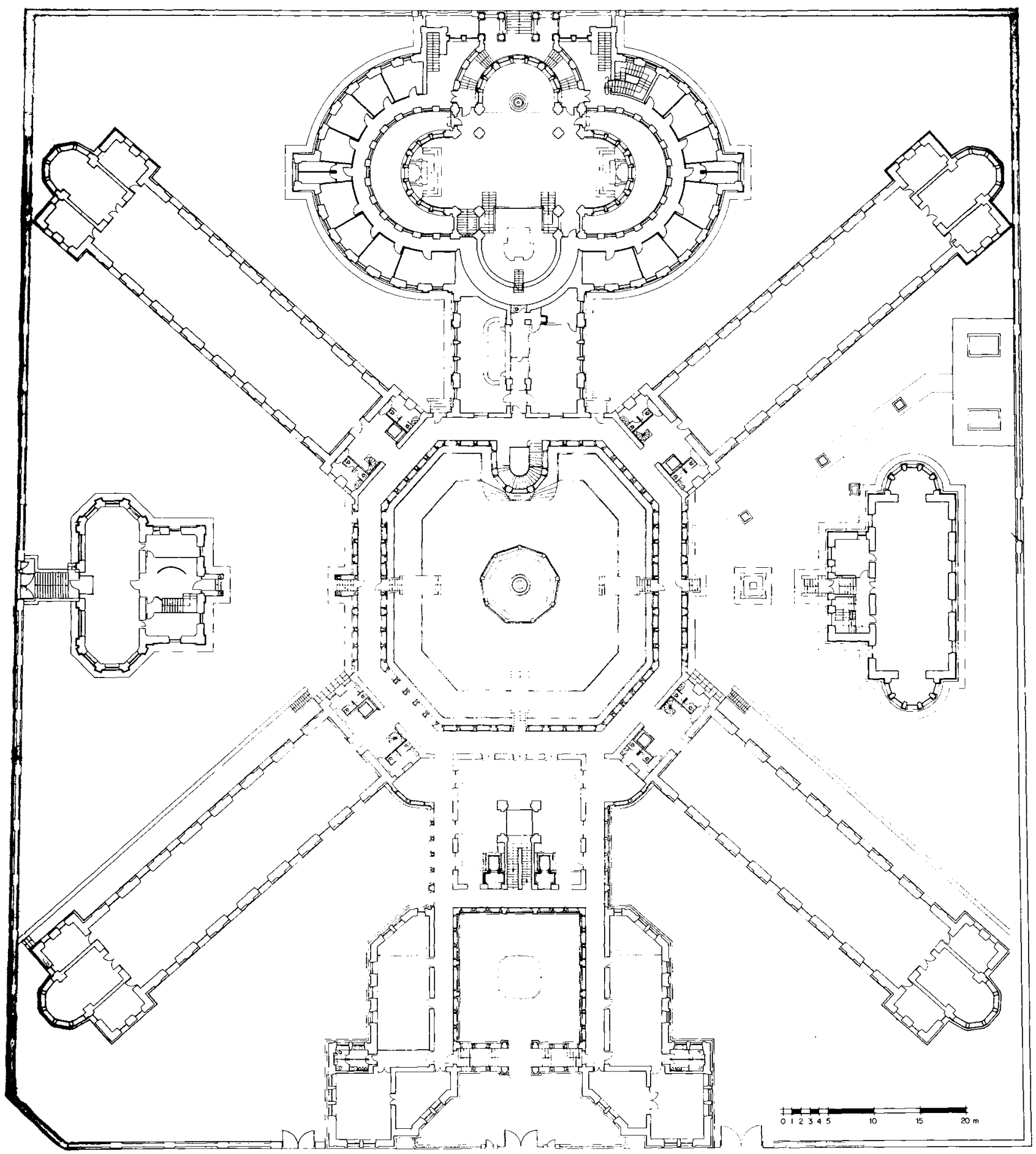

Planta primera.

Desde esta óptica es comprensible el desinterés del proceso constructivo por condicionantes productivos, hoy incuestionables, como son los derivados de un rigor geométrico básico o de una sistemática modular y dimensional, todo lo compleja que se quiera, pero evidente y operativa.
El Hospital de Maudes es paradigma de la arquitectura preindustrial, y como tal es el resultado de un proceso a "mano alzada".

Efectivamente, para la restauración de cubiertas, ha habido grandes dificultades de encaje de un embaldosa- 
do de $50 \times 50 \mathrm{~cm}$ dadas las diferencias dimensionales y las faltas de ortogonalidad de los elementos del edificio; el doble acristalamiento previsto en el proyecto de reposición de vidrieria, ha tenido que abandonarse dada la imposibilidad de ajustar el proceso netamente industrial de fabricación de paños de doble acristalamiento a una carpintería hecha en obra en la que no sólo ventana a ventana, sino ni siquiera un vano a una hoja, guarda suficiente conexión geométrica. La realización de los solados ha sufrido las consecuencias angulares y dimensionales de una base geométrica llena de arbitrariedades.

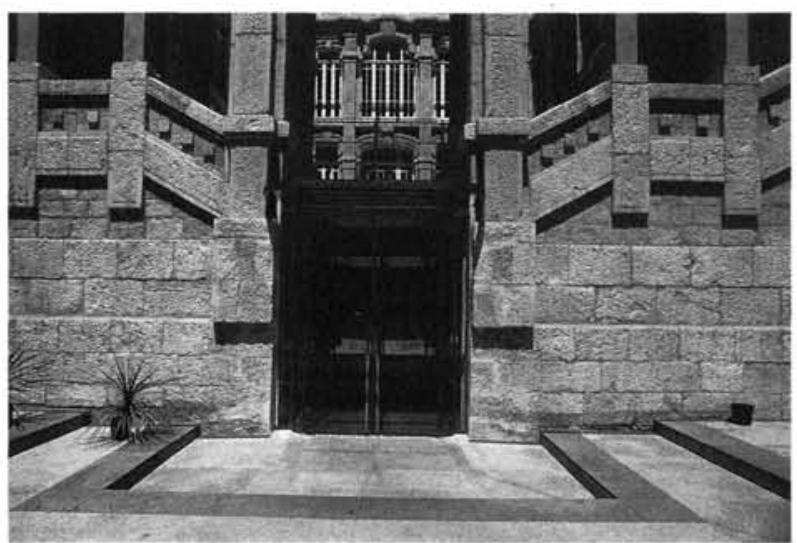

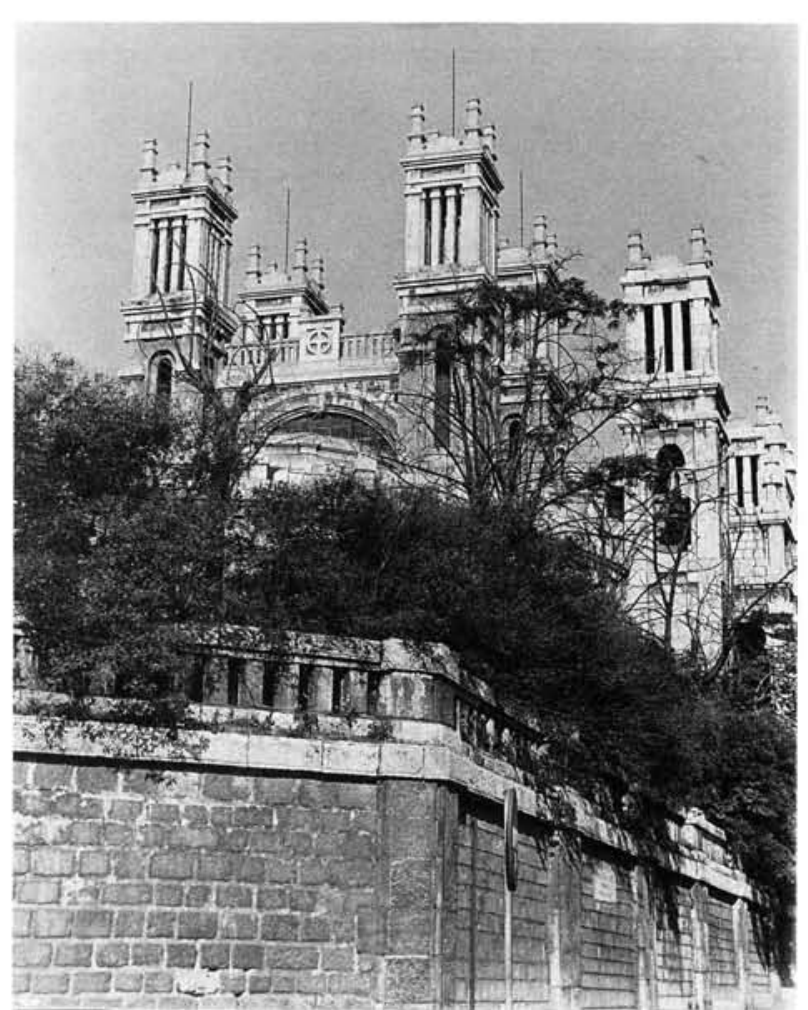

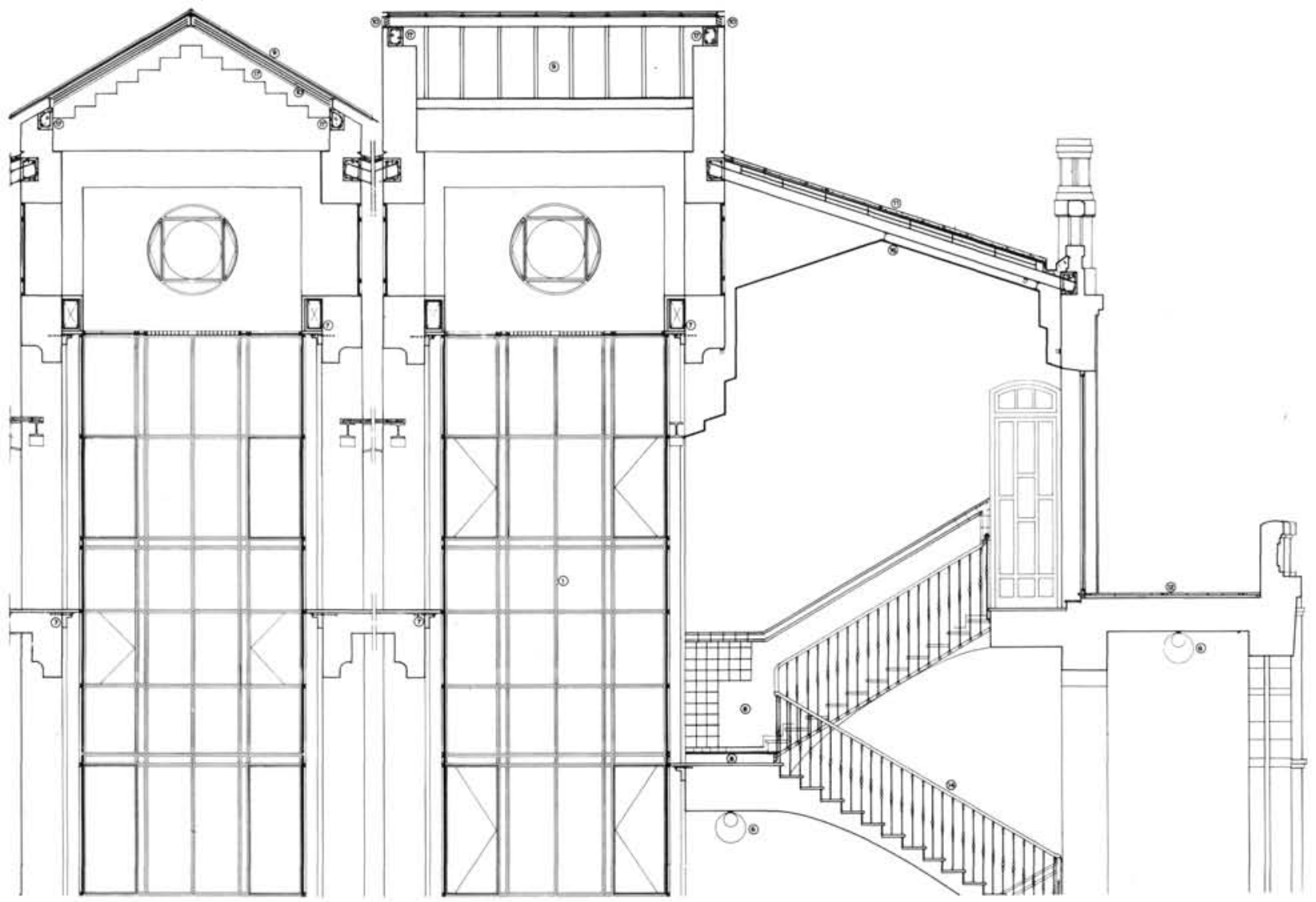

Sección detalle del pequeño patio de ventilación. 
Coherentemente al abordar el proyecto ha sido ponderada la necesidad de recuperar, en la medida de lo posible, no sólo los procedimientos artesanales o semiartesanales de construcción, sino el concepto de diseño continuo que empieza en el anteproyecto original de Palacios; en el proceso proyecto-construcción consiguiente y en el que hoy se cumple una etapa más de un proceso abierto.

Esta rehabilitación se ha dirigido a recuperar, mediante la restauración literal los aspectos más notables y emblemáticos del edificio original, y a terminar elementos inconclusos muy evidentes y otros no tan evidentes pero sin duda en los que, de haber contado con medios económicos o tecnológicos suficientes, lo hubiera realizado de distinta manera.

Este ámbito de culminación discreta de elementos inacabados o mal acabados se completa con la prudente revisión de aspectos degradados respecto de la obra

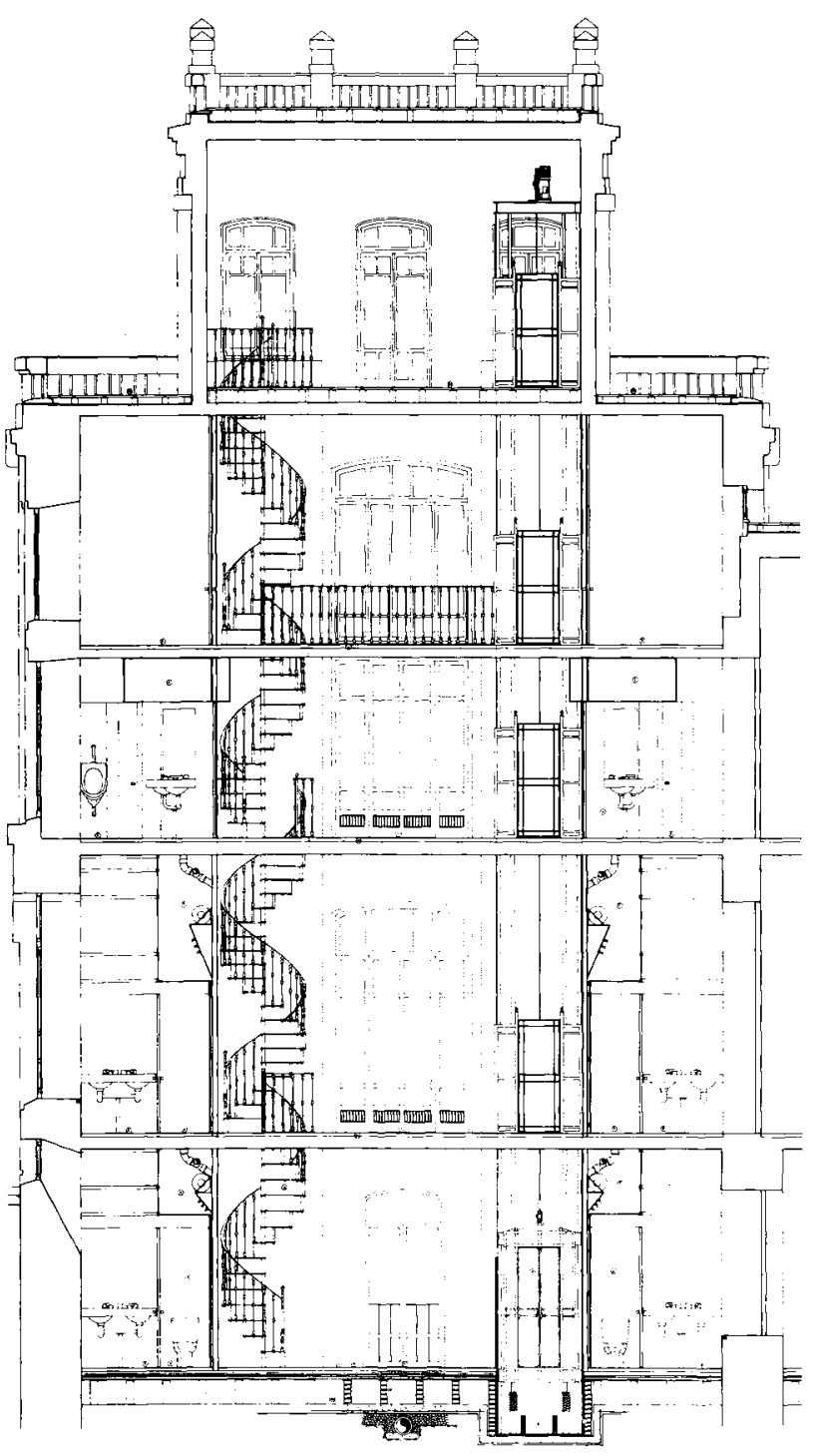

Sección

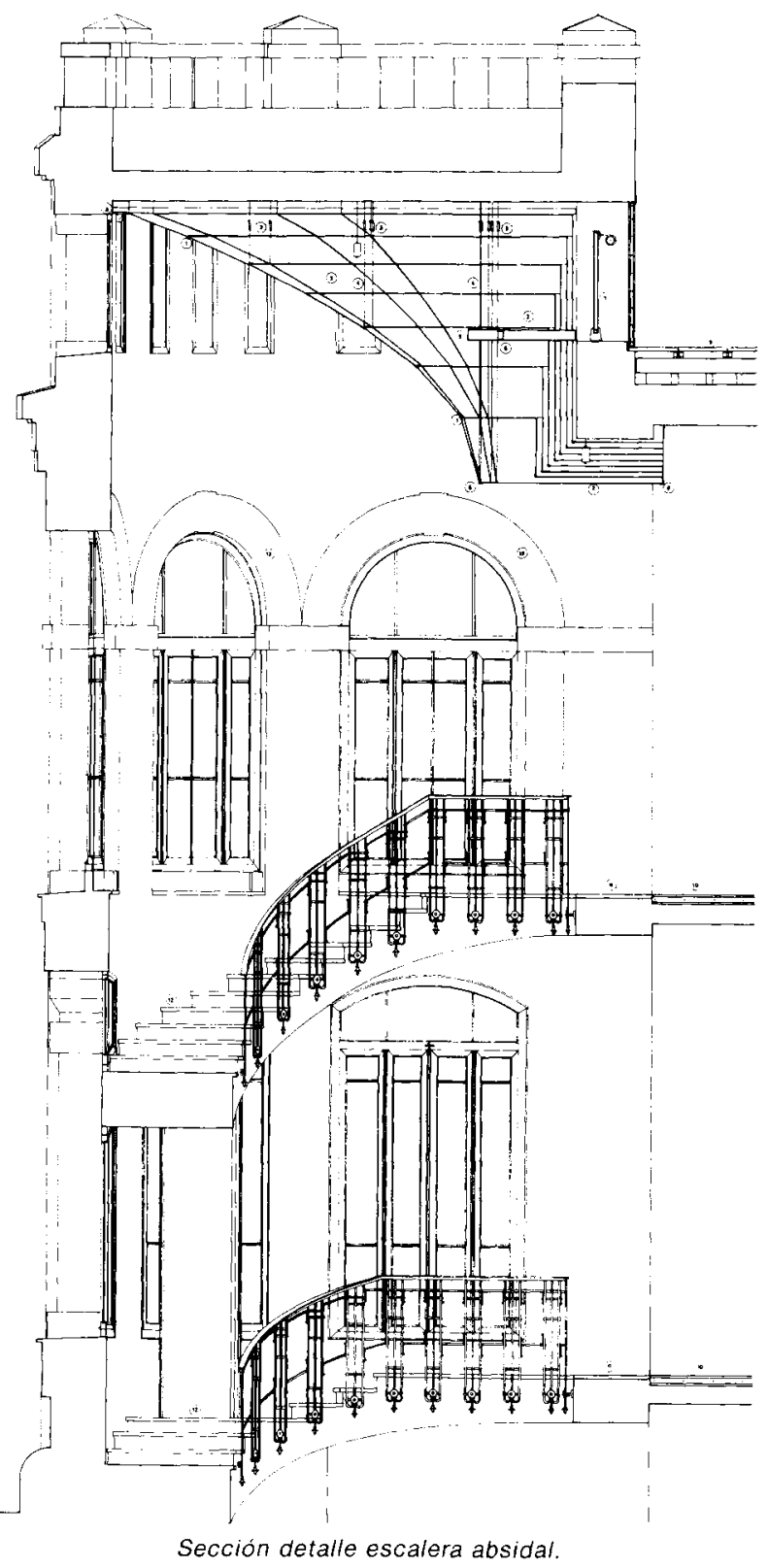

completa o que no alcanza el nivel de calidad general del edificio. La actuación es prudente respecto de los precedentes tectónicos, pero es firme tanto en la op. ción histórica de nuestro tiempo como en la confian. za de que Palacios hubiera reflexionado sobre su reciclaje desde el mismo proceso de la historia.

La Rehabilitación realizada asume la imperiosa inexcusable exigencia de contener una actividad burocrática que supera la capacidad de soporte del edificio original.

Ninguna objección puede hacerse a este propósito ya que funcionalmente el edificio nación obsoleto para el uso de hospital. Las técnicas hospitalarias en la primera década de siglo exigían ya modelos de organización notablemente diferentes al esquema de este hospital. 
La actividad institucional es indudable que precisa minimos de intervención propios, fundamentalmente, de los criterios de confort para el trabajo y la gestión y de los intrínsecos de su función pública, adecuadas a los problemas de accesibilidad, ambiente, inherentes a un edificio que funciona "hacia afuera" bien diferente de las de un edificio "hacia adentro". Concepto original del Hospital de Maudes.

Solventar los problemas de distintos tipos de accesibilidad propios de su uso institucional y público, ha exigido el diseño de mecanismos de comunicación vertical, nuevos accesos y optimización de los existentes.

Los accesos han sido revisados de la siguiente forma: accesos rodados y aparcamiento en los patios laterales a Maudes. Espacios que ya tenian esta función en los últimos años de actividad hospitalaria.

Un acceso de importancia en el eje de Maudes con capacidad suficiente para un vestíbulo de control de la entidad tanto funcional como significativa que el edificio requiere. Esta ha sido la actuación más "dura". Y ante otras opciones como cubrir y cerrar el patio de Maudes, optamos por excavar un espacio más obvio en la secuencia de acceso y en las exigencias de penetrabilidad inmediata a ciertos servicios. La sustitución del primer tramo de escalera del antiguo acceso por una ligera cancela de vidrio se decidió tras un amplio debate y como resultado de asumir la significación de la nueva actividad del edificio en su acceso principal, decantándose la solución realizada entre otras más prudentes pero también más equívocas.

Para el vestíbulo "excavado" se estudiaron otras soluciones entre las que algunas como la gran vidriera soportada por vigas de vidrio templada, permeable a la visión recíproca del patio-vestíbulo, parecieron excesivamente radicales y duras; la solución realizada ha pretendido valorar parcialmente esta doble visión e introducir un tránsito de penumbra-luz-penumbra que dilate espacialmente la secuencia de acceso.

Los accesos restantes al edificio han sido organizados para permitir, puntualmente, cierta especialización y accesibilidad diferenciada a determinadas actividades.

En el pabellón con fachada a Treviño, antigua consulta externa y quirófanos, hemos ubicado la biblioteca de la Consejería de Ordenación del Territorio. Utilizando el acceso original desde la calle y la pasarela que lo une a nivel de la primera planta con el resto del edificio, hemos organizado un doble acceso; para visitantes exteriores desde la calle, para funcionarios y personal adscrito desde el edificio. Hemos relacionado el espacio interior del pabellón con una escalera de nueva construcción, que hemos pretendido extremadamente ligera, dentro de un espacio que totaliza toda la al- tura de este edificio y que explica espacialmente su accesibilidad total.

El pabellón de la calle de Alenza, antigua sección de enfermos infecciosos, contiene ahora el área de exposiciones y actividades culturales de la Consejería. También se han conectado los distintos niveles del mismo con la construcción de una escalera interna y hemos resuelto su acceso, eventualmente, directo desde el exterior habilitando el cuarto de autopsias y velatorio de la calle Alenza como vestíbulo de información. La galería que servía este cuarto desde el Hospital ha sido reformada y ampliada para relacionar el vestíbulo de Alenza con las salas de exposiciones.

Otras exigencias funcionales propias de este uso han determinado la necesidad de proyectar varios sótanos para almacenamiento de fondos documentales 0 culturales.

La distribución administrativa y el objetivo de respetar la diafanidad de los ambientes fundamentales conlleva la construcción de entreplantas para salas de reuniones o el diseño de salas de reunión y esparcimiento complementarias de la actividad meramente productiva.

No obstante, este último nivel de actuación ha sido muy restringido tanto por un prudente respeto a las características arquitectónicas del antiguo Hospital, como al convencimiento de que el tiempo es una dimensión distinta en la proyectación postindustrial, de la preindustrial y que la propia metodología de trabajo conllevaba una función real entre la decisión proyectual y la realidad edilica. En este proyecto se ha intentado penetrar en aquella forma de trabajo desde la propia elaboración en "campo" del diseño, pero a pesar de ello no es posible aproximarse a aquellas condiciones metodológicas sino con la restitución literal del proceso; ya desde el diseño mediante la comprensión de este acto como sometido a alternativas posibles abordables incluso durante el proceso de adjudicación del proyec. to. Después de realizado y construido, to hecho se reduce a sus mínimos y ha sido decidido como un paso previo y condicionante a revisiones y actuaciones posteriores no sólo posibles, sino deseables.

Resumiendo, los criterios de actuación que han dirigido el proyecto en los distintos niveles de intervención han sido los siguientes:

\section{Nivel de Restauración}

Restauración estructural. El criterio seguido ha sido su reparación literal conforme a las caracteristicas de su estructura original. Los elementos dañados, generalmente vigueria metálica, se ha sustituido pieza a pie. 
za mejorando condiciones de apoyo en general deficientes. Cabe destacarse, no obstante, la conversión de la forma de trabajo de ciertas piezas y conjuntos para optimizar su capacidad resistente y alcanzar las prestaciones que la nueva actividad exige. En las jacenas de primer y segundo forjado de las naves fueron hormigonadas cabezas de compresión haciendo de ellas vigas mixtas y tranformando los forjados en elementos hiperestáticos con las consiguientes optimizaciones de flecha y minoración de momentos de trabajo.

La antigua cubierta del cuerpo que une el Hospital y la Iglesia fue transformada, por simple soldadura de pares y viguetas de forjado, en la cubierta de "tijera". Esta modificación permitió la demolición de los muros de apoyo cuyo peso era mayor que las bombas de calor alojadas en este espacio.

Restauración arquitectónica. Los elementos arquitectónicos deteriorados se han restaurado recuperando sus características originales, no sólo por el indudable valor plástico de las mismas, sino porque en el cor. to periodo de tiempo que ha dispuesto el proyecto, respecto de los procesos preindustriales, no pueden asumirse decisiones no reflexionadas literalmente, por
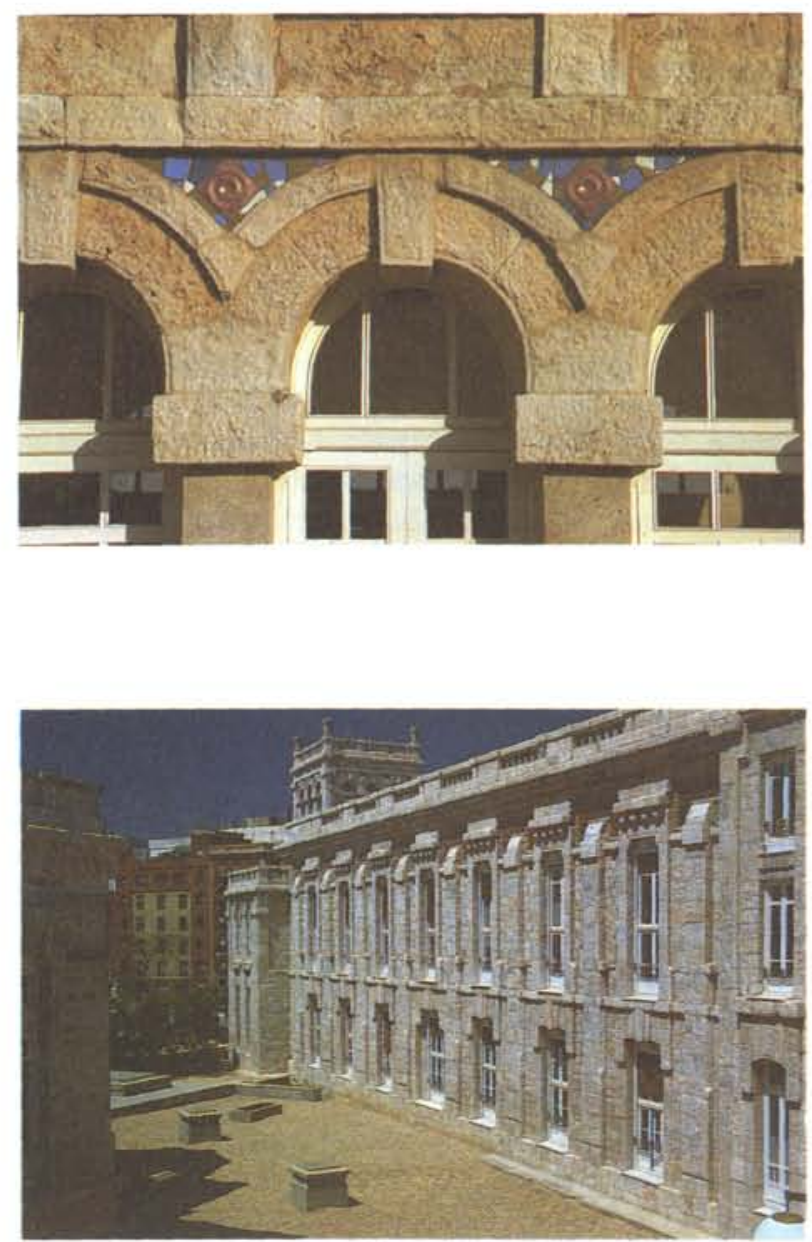

(C) Consejo Superior de Investigaciones Científicas Licencia Creative Commons 3.0 España (by-nc)

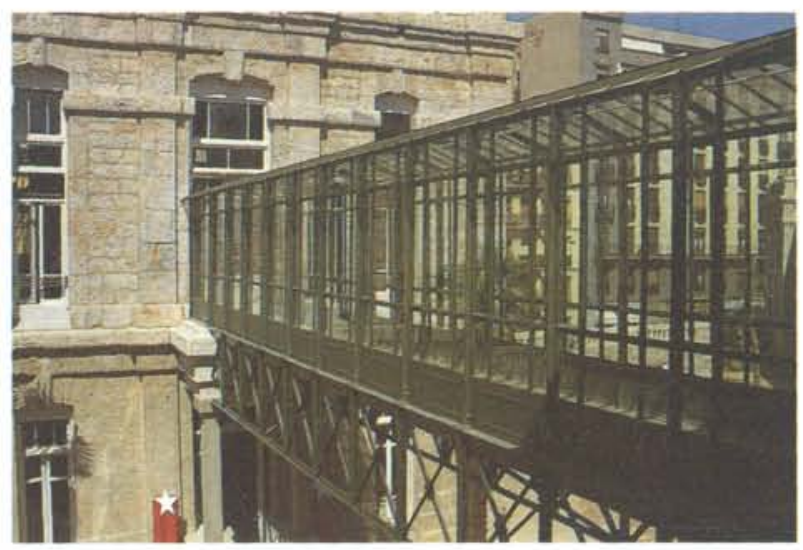

ejemplo; el relleno de los intradós de las arquerias con cerámica en los torreones de las alas diagonales y en general en esta restauración se aborda con las mismas técnicas del proyecto original.

La limpieza de fachada, restauración de carpinteria, cerámicas, persianas, cerrajería, restauración de elementos complementarios, balcones, escaleras, rejas, etc., han sido realizadas con el propóisto de poner, en valor, la expresión arquitectónica original del Hospital de Jornaleros.

\section{La rehabilitación estructural del edificio}

Es abordada como una prolongación proyectual del concepto relativo estructura-espacio arquitectónico. La necesidad funcional de disponer espacios suficientes de almacenamiento ha demandado el proyecto de espacio bajo rasante en las alas del edificio, aparte de diferentes soluciones para contención y realce del edificio existente con muro de contención, se ha proyectado como techo de estos sótanos y suelo estructural de planta baja una lámina parabólica del hormigón que obviamente denota el gesto estructual único aprendido de la cobertura del techo superior de la nave. Entreplantas, escaleras, y otros elementos estructurales han sido definidos con la mayor brillantez posible dentro de una respuesta económicamente viable y de la necesaria naturalidad formal para no perturbar el carácter del espacio arquitectónico. En ningún caso, no obstante, se ha eludido el compromiso de un diseño cultural y productivamente situado en el último cuarto del siglo, potenciando, por el contrario, la disponibilidad de conocimientos científicos y materiales que permiten afinadas dimensionales más estrictas que las que utilizó Palacios. Tal es el caso de las escaleras y pasarelas de Treviño o los lucernarios del vestíbulo de acceso y del pequeño patio central. Rehabilitación estructural, por tanto, abordada con el criterio de gestos estructurales inteligibles y de claridad preceptiva tanto conceptual como tecnológicamente. 


\section{La rehabilitación espacio funcional}

La rehabilitación espacio funcional del edificio ha sido entendida bajo el criterio de optimizar el equipamiento y acabados de confort y reciclar elementos inadecuados y obsoletos con el mínimo de actuación posible. Siempre en actos muy condensados situados en el plano de lo "mueble" con la intención de subrayar los valores más intemporales de lo inmueble fundamentales en el edificio de Palacios.

Esta rehabilitación espacio-funcional se plantea como respetuosa respecto de los valores especiales del antiguo Hospital, incluso para liberarlos de las servidumbres funcionales a las que su antiguo uso sometió.

De acuerdo con lo dicho ha sido demolida la tabiqueria hospitalaria redistribuyendo los espacios resultantes con las minimas particiones posibles aunque ello conlleva alguna molestia operativa en el funcionamiento institucional. Han sido utilizados los espacios ya compartimentados en origen y que trascienden al exterior para alojar los despachos ineludibles núcleos de aseos y funciones necesariamente separables de los ambientes globales de trabajo. Sobre esta ubicación predeterminada han pivotado todos los esquemas de distribución funcional. Las restantes particiones espaciales se plantean como subdivisiones en el ámbito, otra vez, de lo "mueble" no sólo por su flexibilidad, sino por cuanto supone evitar competencias de lenguajes arquitectónicos con las preexistencias de mayor entidad.

Esta opción permite remitir al mobiliario burocrático la fragmentación del espacio y posibilitar el control formal del equipamiento posterior que invalidaria, en caso contrario, los mejores propósitos y logros de la actuación arquitectónica.

Los criterios de flexibilidad funcional que respetados al máximo, permitirian establecer las condiciones para un largo ciclo de servicio, exige plantear los sistemas de servicio tecnológicos adecuados a cualquier

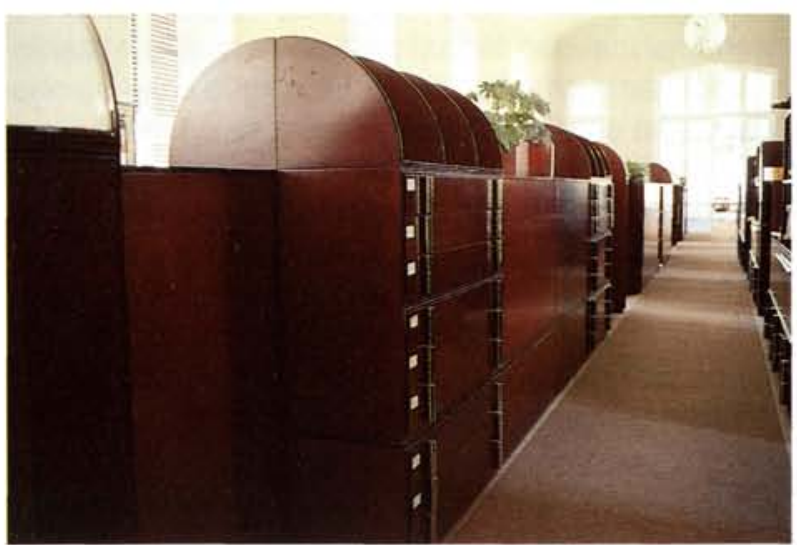

(C) Consejo Superior de Investigaciones Científicas Licencia Creative Commons 3.0 España (by-nc)

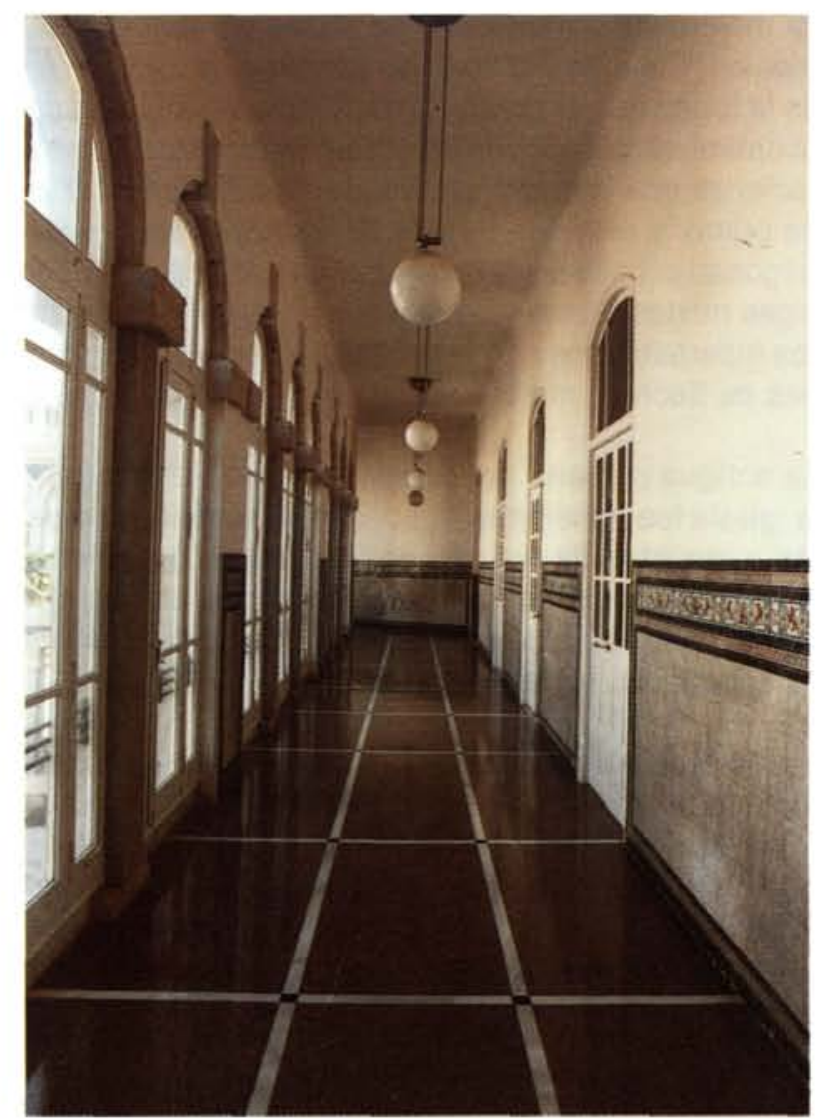

posicionamiento funcional, por ello tanto la climatización como las redes eléctricas y de comunicación son isótropas respecto del espacio servido. Cualquier punto operativo se encuentra, así, servido en las mismas condiciones que cualquier otro para alojar la función administrativa prevista.

Ello conlleva dos exigencias correlativas: La primera de ellas, la no compartimentación del espacio global para permitir ventilaciones eficaces y homogéneas. La segunda, determina alcanzar los niveles de absorción acústica exigibles a los pavimentos, muebles, y techos que reducen notablemente el arco de acabados posibles a aquéllos elásticos y altamente absorbentes (moquetas y revestimientos acústicos). Es especialmente interesante todo el trabajo realizado en la adecuación acústica de los espacios laborales y cuyo resumen se adjunta a este trabajo.

En algunos puntos la rehabilitación ha avanzado especialmente por distintas razones, asi en el pequeño patio de luces del cuerpo central, antes espacio estrictamente funcional y como tal excesivamente residual en el proyecto de Palacios, requiere ahora alcanzar sus máximas posibilidades de luz y ventilación de acuerdo con las actuales exigencias laborales y se convierte en un espacio aúlico y conceptual como un prisma de luz en toda la altura del edificio. El remate de la escalera posterior es otro elemento inconcluso que hemos resuelto con un techo-luminaria articulando el espacio de la 
escalera con la galería y con el acceso a la sala de juntas situada en este encuentro.

En los accesos a las naves diagonales han sido reconstruidas las dotaciones de aseos y transporte vertical originales. Los aseos con mayor dotación de servicios que los precedentes resueltos con cabinas de formica y falsos techos de policarbonato celular. Los elevadores como cajas de vidrio que permitan visualizar el espacio de estos auténticos uartex de acceso en toda su altura.

\section{LA TECNOLOGIA UTILIZADA}

Las prestaciones exigibles en la actividad burocrática moderna exigen de esta rehabilitación una atención especial al equipamiento funcional. Los objetivos de flexibilidad y optimización de los condicionantes espaciales, de esta suerte tanto las instalaciones interiores y telefónicas han de ser accesibles desde cualquier punto y redistribuibles según las variaciones funcionales de las oficinas que se preven.

Por otra parte, consultados especialistas en el tema, pareció como única alternativa posible para la climatización, dadas las condiciones de volumen interno, la flexibilidad e imposibilidad de introducir conductos de gran sección en el espacio arquitectónico y la climatización por fankoils en línea casi continua o suelo radiante. Esta última ha sido la solución adoptada tanto para calor como para enfriamiento estival, completado con un ocasional, en horas punta, tratamiento de aire primario. Las características del sistema se describen en el anexo de la memoria correspondiente pero aqui destacamos su adecuación funcional $y$ arquitectónica.

La coordinación de todos estos servicios sobre el espacio se realiza con un sistema de doble peine: uno primario de amplios paños de suelo radiante servido por dos vias de distribución a lo largo de los nervios y otro de canales de servicio en suelo en los que alojar líneas de energía eléctrica y alumbrado, servidos éstos por una via central. El suelo, así, aloja una red multifuncional, seccionable, alterable y flexible. La conservación y reparación de este sistema es elemental y permite su bloqueo parcial sin interrumpir el funcionamiento conjunto.

Mención aparte merece el diseño de alumbrado general. La experiencia en diseño de espacios de trabajo enseña la necesidad de prever necesariamente la luz de trabajo sobre el puesto productivo y una iluminación complementaria, ambiental con nivel suficiente para un tipo de actividad general. El proyecto prevé disponer en las áreas de trabajo una iluminación por equipos fluorescentes de la potencia necesaria como luz ambiental y supeditar el alumbrado de cada punto de tra. bajo la iluminación de la intensidad necesaria para el trabajo burocrático.

Las áreas de circulación, con mayor razón, se resuelven con el mismo concepto original de globos repartidos uniformemente que además tienen el valor secuencial de su carácter puntual y la forma indiferenciada que la diversidad de ambientes exige. No importa que es. tas circulaciones tengan un nivel lumínico "pobre" es, sobre todo, una recuperación ambiental importante. Las escaleras delantera y posterior tienen un tratamiento específico dado su carácter singular.

Hemos integrado en un único aparato, el detector de incendios, el alumbrado de emergencia y la iluminación general de los distintos ambientes.

La iluminación del jardín se resuelve mediante luminarias esféricas con soporte metálico repartidas regularmente y dispuestas para, aparte de señalar puntos de acceso significativos, producir un nivel lumínico muy discreto de los suelos exteriores. De este resplandor general emerge en penumbra la masa del edificio.

La producción de energía ha sido resuelta mediante bombas de calor situadas en la cubierta del cuerpo que une Hospital e Iglesia. Tanto este equipo como el resto de elementos de toma de aire y expulsión de aire sobrante o viciado ha sido resuelto evitando la aparición de conductos y otros objetos que perturben el exterior del edificio.

Todas las instalaciones se contienen en espacios accesibles. Una galeria general para las redes principales, conecta con cámaras y patios de instalaciones de forma que todos los puntos del edificio pueden recibir servicio de sistemas no previstos inicialmente o modificar su situación cuando se estime oportuno.

De hecho la instalación posterior del servicio informático ha comprobado la accesibilidad a todos los puestos de trabajo desde cualquier punto del edificio.

Los acabados que han definido las terminaciones de la rehabilitación han respondido o bien a exigencias de tipo ambiental (acústicas, proyectados de vermiculita y moquetas) o funcional (tendidos de aglomerado de corcho, revestimientos de formica, etc.)

Queremos destacar como experiencia particular de esta rehabilitación la utilización del terrazo in situ con juntas tajeadas de mármol para las zonas de circulación, el "alfombrado" realizado en las cubiertas con las baldosas flotantes de protección del impermeabilizante, la utilización exhaustiva del tablero de fibras tanto teñido (muebles ascensores, aseos de conserjes, etc.) como en su color (sala de juntas, despachos de consejo, etc.) y la optimización del forrado de formica en suelos y muros de la sala de exposiciones de Alenza. 


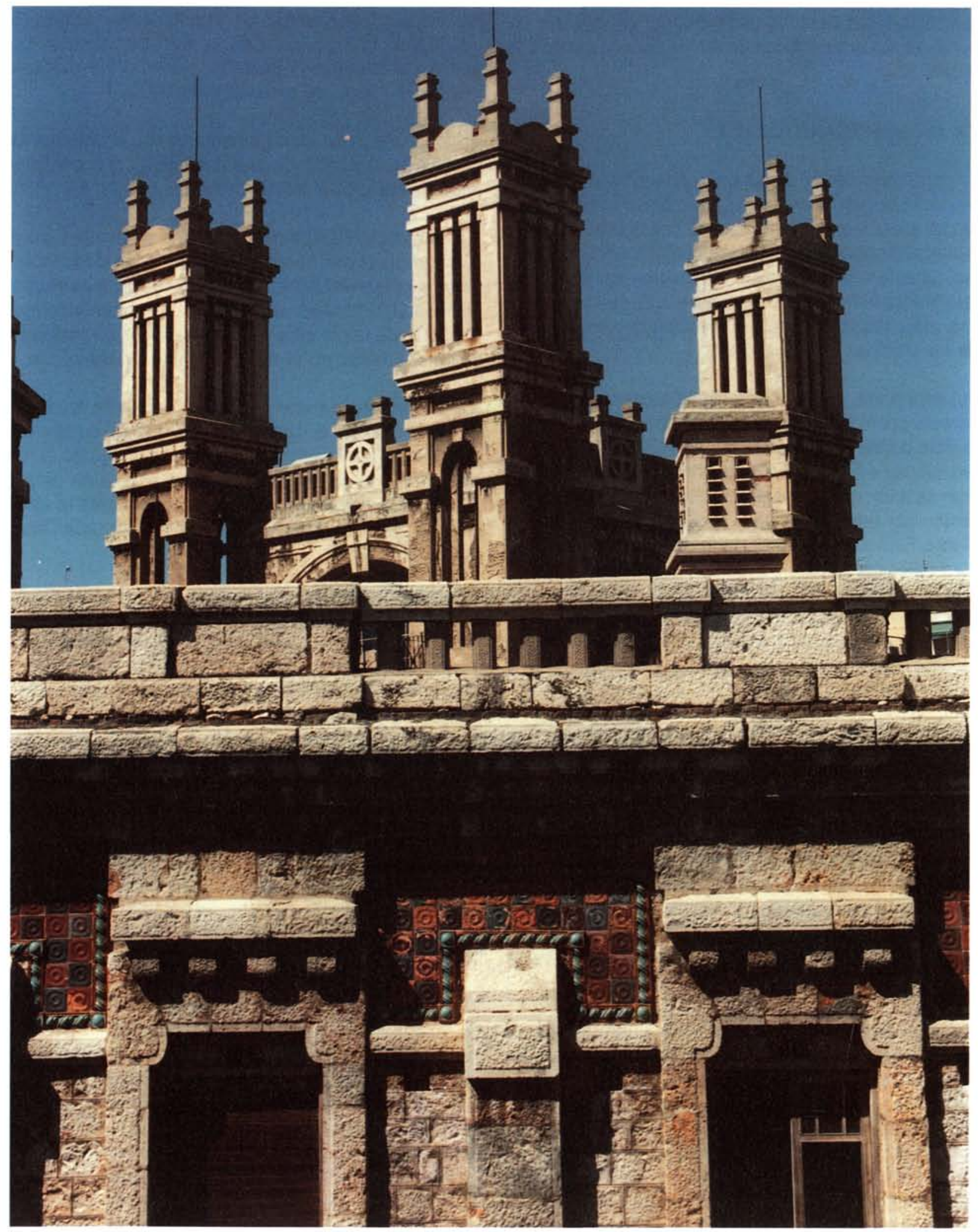



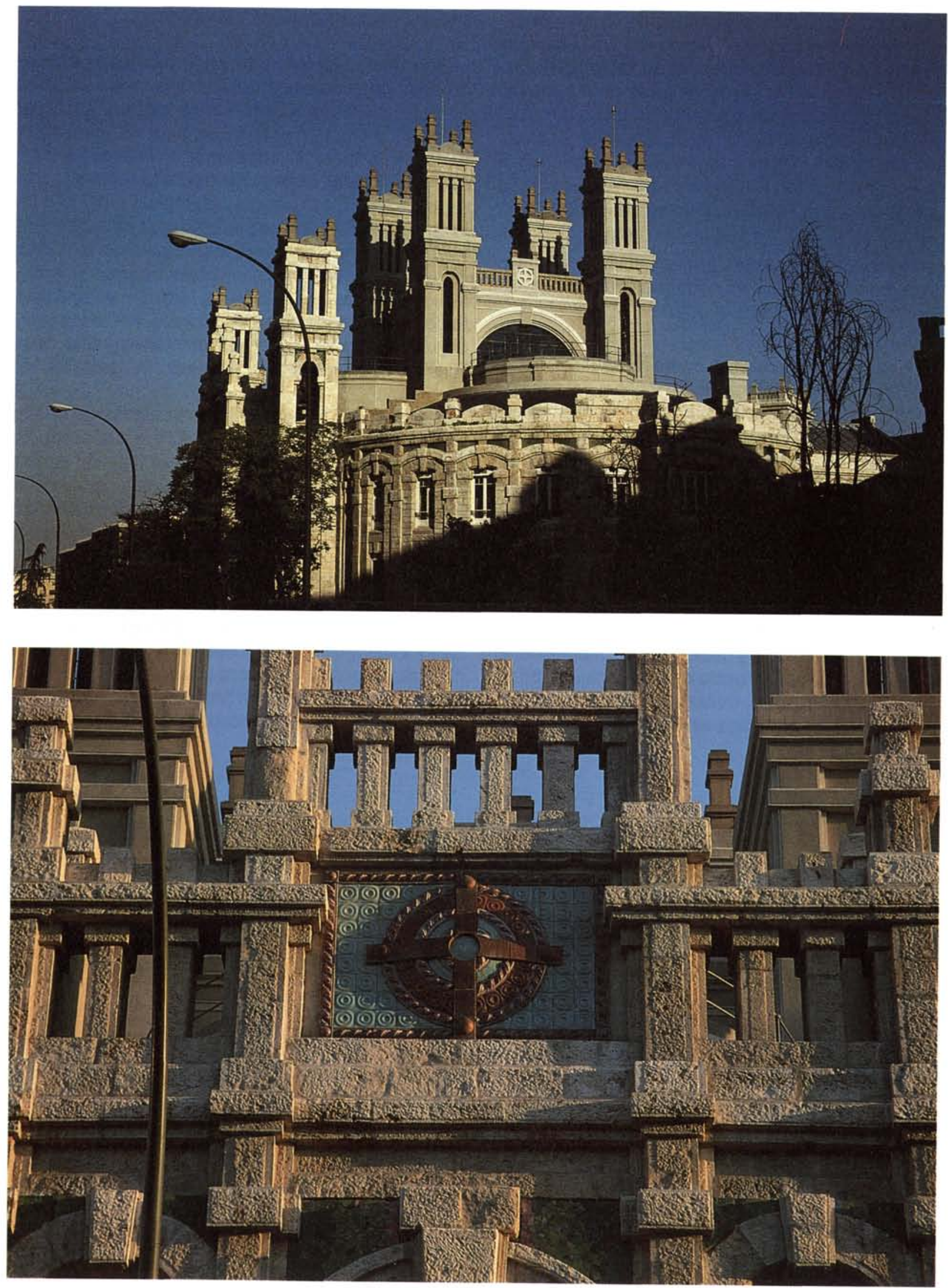
Se han respetado los acabados de la cafetería y la sala contigua y el solado de mosaico de mármol de Alenza como testimonio de los revestimientos originales.

Un importante aspecto de la restauración exterior del edificio ha sido el trabajo realizado con las cerámicas originales de Zuloaga, detallada en otro apartado de este texto, y la completación de los paños de las enjutas de los arcos preparadas para este fin y que por razones desconocidas no fueron realizadas en la construcción del edificio. Hemos interpretado el juego cromático y su tratamiento textural a partir de los arcos de los torreones que Palacios sí completo en su dia.

Los colores básicos, verdes, azules y malvas pretenden responder a la escuela centroeuropea en la que en muchos aspectos se miraba el autor.

Esta rehabilitación entiende como inexcusable abordar el problema del equipamiento mueble del espacio rehabilitado como un tema prioritario. Una excelente actuación sobre lo inmueble, la arquitectura y el espacio por ello definido puede degradarse si no es controlado el mobiliario consiguiente. Más aún, una actuación liberadora del espacio como ésta que aqui se propone no admite un equipamiento que no haya sido dirigido previamente a vitalizar aquellos aspectos protagonistas del espacio arquitectónico.

Coherentemente con lo expuesto se propuso en el proyecto un sistema global y coordinado de mobiliario. EI elemento básico es el mueble de almacenaje de documentación, información, material, etc., que discernido en elementos muy simples se plantea en toda su ca- pacidad combinatoria definiendo particiones modulares que por si solas acotan funcionalmente un espacio suficiente para el desarrollo del trabajo administrativo y similar; esta partición puede consolidarse con separaciones adicionales más ligeras.

La versatilidad de esta propuesta y su integración en la arquitectura es evidente. Los elementos de mobiliario consiguientes son las mesas de trabajo para las que se proponen un primer tipo apto para trabajadores de auxiliaria administrativa que están sometidos a una frecuente mobilidad respecto a su puesto de trabajo, y un segundo tipo o modelo propuesto está dirigido a los jefes intermedios en dos posibilidades de ancho y dotación de archivo personal, mesas para las máquinas de escribir completan el conjunto que dentro de la sencillez pretende cubrir sin fatiga formal el equipamiento general del espacio arquitectónico. Posteriormente diseñamos otras piezas complementarias: mesas de sala de juntas, muebles para ordenador, mostradores, etc.

Creemos que el trabajo realizado ha alcanzado niveles satisfactorios sobre todo en la difícil incardinación de las instalaciones en la fábrica del edificio sin subvertir la entidad espacial del mismo. El equipamiento de mobiliario y servicios ha respondido en nuestro entender a los objetivos que se pretendia alcanzar. El resto de las actuaciones más o menos intensas, según distintas localizaciones del conjunto, han obedecido al propósito de adecuar un contenedor obsoleto a la actividad administrativa programada. En ello hemos sido fieles a nuestro siglo y a la exigencia de responder con naturalidad pero con firmeza a la necesidad de reconvertir uso y carácter de un problemático legado de la historia de nuestra Arquitectura.

\section{publicación del i.e.t.c.c.}

\section{ACUEDUCTOS ROMANOS EN ESPAÑA Carlos Fernández Casado Prof. Dr. Ing. de Caminos, Canales y Puertos}

Esta publicación se compone de una serie de articulos, publicados en la Revista "Informes de la Construcción", en los cuales se hace un análisis de los acueductos romanos que existen en España y el balance de las condiciones de conservación en que se encuentra cada uno de ellos, incluyendo referencias históricas y literarias. Se ha ilustrado con la reproducción de la valiosa documentación gráfica que posee el prestigioso autor.

Un volumen encuadernado en couché, a dos colores, de $21 \times 27$ centimetros, compuesto de 238 páginas, numerosos grabados, dibujos, fotos en blanco y negro y figuras de linea.

Precio: España, 900 ptas., 13 \$ USA.

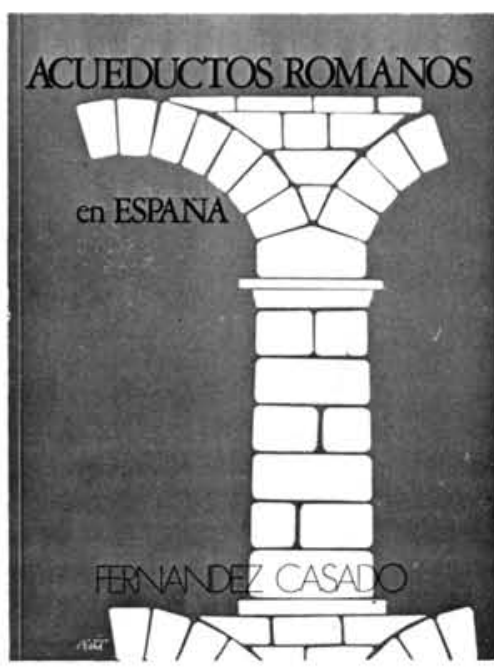

